\title{
TEMPERATURE OF SOIL MONITORED AT EXPERIMENTAL SITES IN PERM REGION (RUSSIA)
}

\author{
Andrey Ponomaryov*, Aleksandr Zakharov \\ Perm National Research Polytechnic University, Kuibysheva street 109, Perm, Russia \\ * corresponding author: spstf@pstu.ru
}

\begin{abstract}
The paper presents the monitoring results for soil temperatures in the geological and climatic conditions of the city of Perm (Russia). The monitoring results are presented for two experimental sites. Site 1 is characterized by dense urban development and related to type I soil conditions in Perm (the left-bank area of Perm). Site 2 is located in a low-urbanised region of the city and is related to type II soil conditions in Perm (the right-bank area of Perm).
\end{abstract}

KEYWORDS: Temperature of soil, monitoring site, energy-efficient foundations.

\section{INTRODUCTION}

The Department of Construction Technology and Geotechnics of Perm National Research Polytechnic University has conducted studies of the temperature fields on ground bases in the city of Perm since 2009. Research is being carried out to quantify the thermal behavior of soil for the main types of geotechnical condition.

Quantitative assessment of subgrade temperature is one of the main factors allowing introduction of a process based on the use of the soil thermal energy. In particular, these are the energy-efficient foundations and underground structures of buildings. As a rule, technologies based on the use of soil thermal energy are employed for the heating and cooling of buildings, at the very least to provide electricity and hot water.

These technologies have been widely used in European and neighboring countries [1 5]. Their introduction in Russia at this point is not yet much in evidence.

\section{Geological SeCtion of EXPERIMENTAL SITES}

Research of temperature fields on ground bases are being carried out for two basic types of geotechnical conditions specific to the left-bank and right-bank areas of Perm city. Studies are being conducted at two sites:

- Site 1

The monitoring system is installed at the Civil Engineering Faculty PNRPU in the Sverdlovsky district of Perm (left bank of the city). Monitoring has been carried out continuously from December 2008 to the present time.

Site 1 is characterized by dense urban development. The development age is more than 50 years. The distance from the observation well to the nearest building is about $3 \mathrm{~m}$.

Taking the results of a geological engineering survey, experimental site 1 is comprised of quaternary alluvial- dealluvial clayey soil of a total thickness of $11.6 \mathrm{~m}$, with up to $60-70 \%$ of pebbles at the bottom. Quaternary soils are overlaid by filled-up ground of thickness $6.0 \mathrm{~m}$.

Filled-up ground is represented by clay soil of semi-solid to plastic consistency at the base with an admixture of $60-70 \%$ of construction waste (rubble, broken bricks, glass, wood).

The bedrock is argillites uncovered at a depth of $17.6 \mathrm{~m}$.

Quaternary alluvial-dealluvial deposits are mainly represented by clay of solid to semi-solid consistency underlying the pebble with loamy sand of solid consistency (the content of gravel and pebbles being $60-70 \%$ ).

The geological section is shown in Fig. 1 1 .

- Site 2

The monitoring system is installed on the territory of the university campus in the Leninsky district of Perm (the right bank of the city). Monitoring has been carried out since August 2015. Currently monitoring data has been obtained up to January 2016.

Site 2 is located on the undeveloped area of the city. The distance to the nearest building is more than $30 \mathrm{~m}$.

According to the results of archival research of the surrounding area, site 1 is comprised of quaternary alluvial sand and clay of a total thickness of $15 \mathrm{~m}$, with $25 \%$ of gravel at the bottom.

Quaternary alluvial deposits are represented by fine sand, clay and clay soils of plastic to liquid consistency. The gravel inclusion was marked from a depth of $1.0 \mathrm{~m}$ along the full thickness of the alluvial soils with an increase to the base up to $25 \%$. According to the results of archive research the bedrock was uncovered at a depth of $17.0 \mathrm{~m}$.

The geological section is shown in Fig. 1p.

According to the results of geotechnical studies sites 

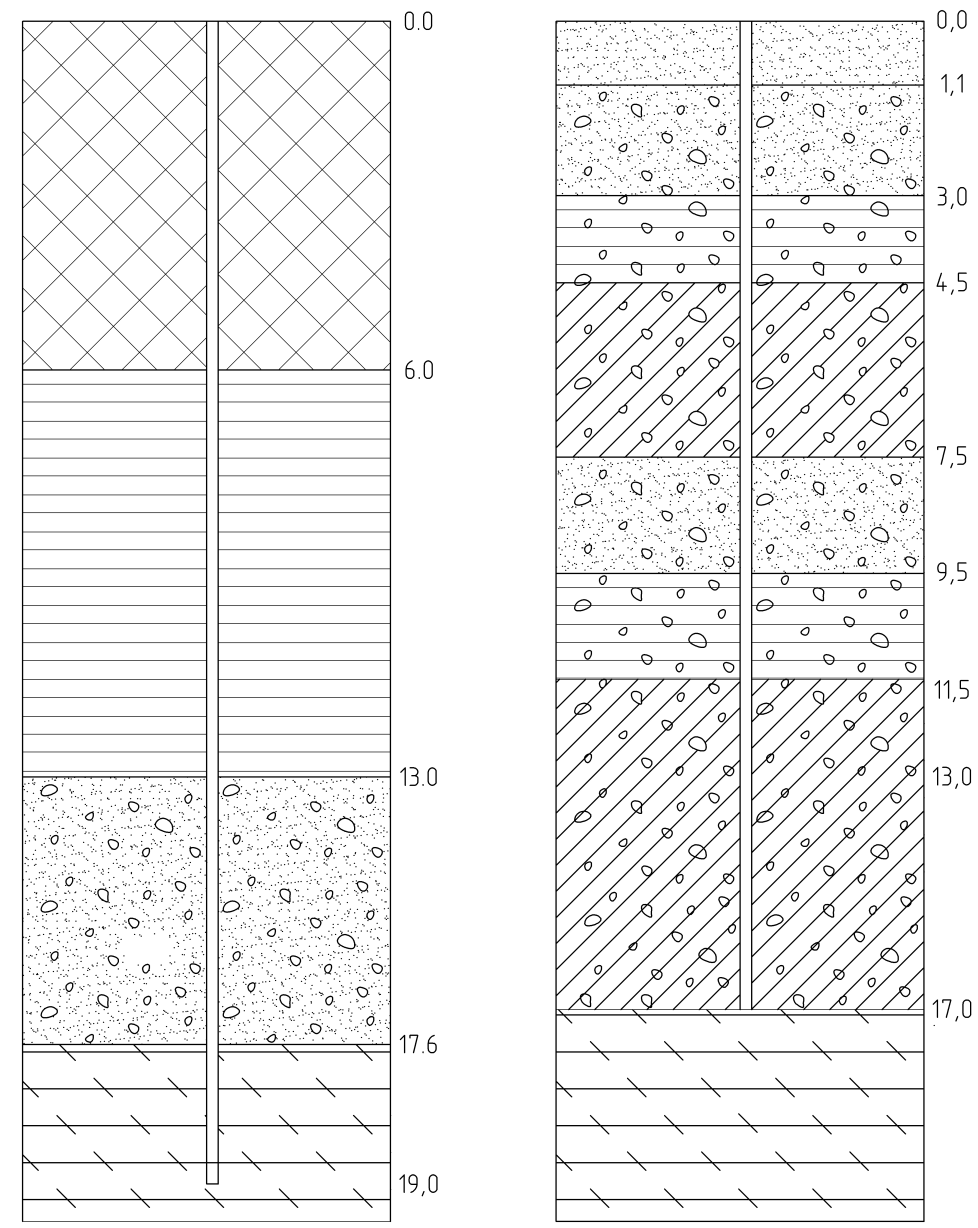

FigURE 1. Geological section of experimental sites

1 and 2 are assigned to the I and II types of geotechnical conditions respectively, specific to Perm [6].

\section{Monitoring Results of The TEMPERATURE FIELDS}

Studies of the temperature field distribution in the soil were carried out by installing a resistive temperature transducer (temperature sensors). Installation of this resistive temperature transducer was made in a predrilled hole with a protective casing.

To gather the data RTM 59 loggers were used for measuring, continuous recording and monitoring of temperature and other non-electrical values (frequency, pressure, flow, level, etc.), converted into electrical signals of strength, DC voltage and DC resistance [7].

The thickness of the observed soil mass on the site 1 is $19 \mathrm{~m}$. The temperature sensors were installed at intervals of $1 \mathrm{~m}$.

Monitoring of temperature fields has been held for more than 5 years on site 1 . The summarized monitoring results (average monthly temperatures for the period from January 2009 to January 2016) are shown in Fig. 2,

As given in the diagram the temperature of the soil mass from a depth of 8-9 $\mathrm{m}$ is practically independent of the seasonal outdoor temperature fluctuations. The temperature is about $12{ }^{\circ} \mathrm{C}$, falling to $10{ }^{\circ} \mathrm{C}$ to the depth of $19 \mathrm{~m}$.

To analyze the temperature fluctuations for several annual cycles the average monthly temperatures in September over the period 2009-2015 is shown in Fig. 3

As given in the diagram the temperature of the soil mass from a depth of 8-9 $\mathrm{m}$ is constant (the difference is not more than $1{ }^{\circ} \mathrm{C}$ ) during 6 years of monitoring. Soil temperatures in September 2015 are explained by abnormally low outside temperatures in summer 2015.

The thickness of the observed soil mass on the site 2 is $37 \mathrm{~m}$. The temperature sensors were installed 


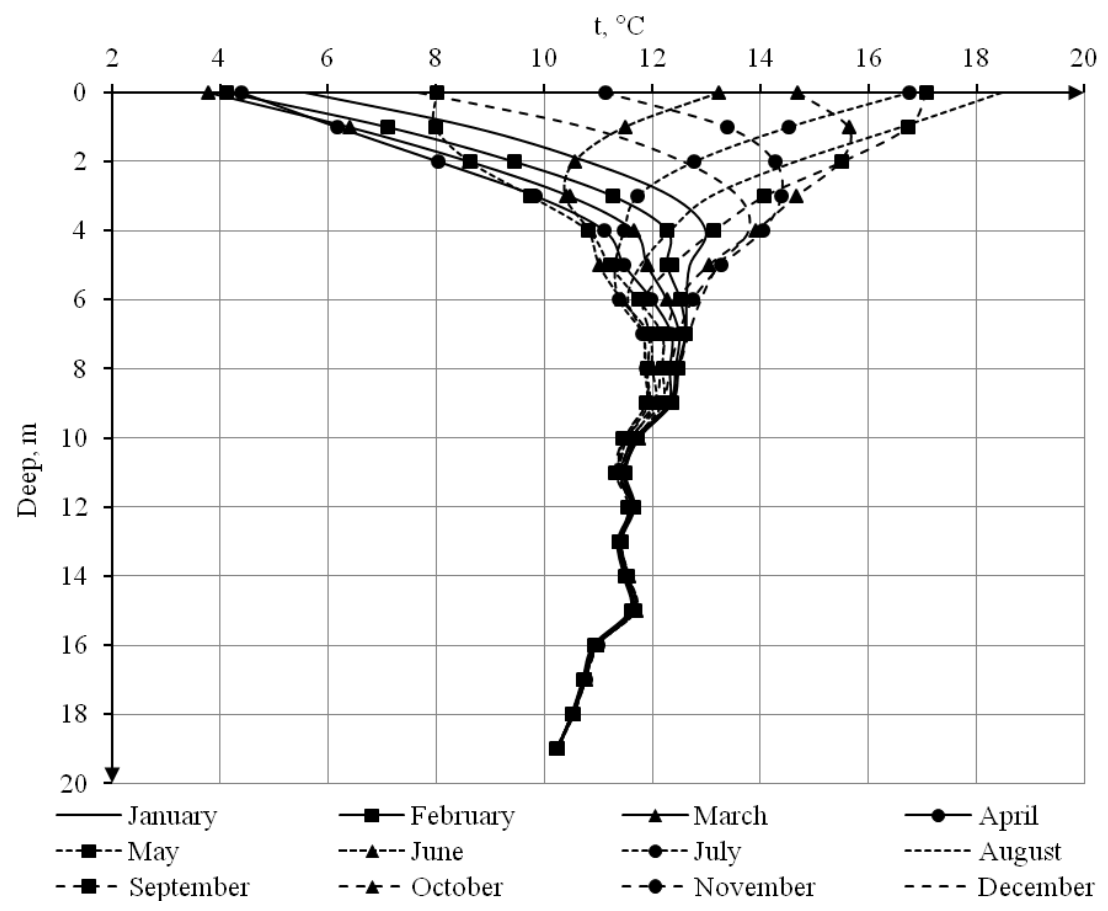

Figure 2. Site 1. Diagram of average monthly temperatures of soil mass according the monitoring results from 2009 to 2016

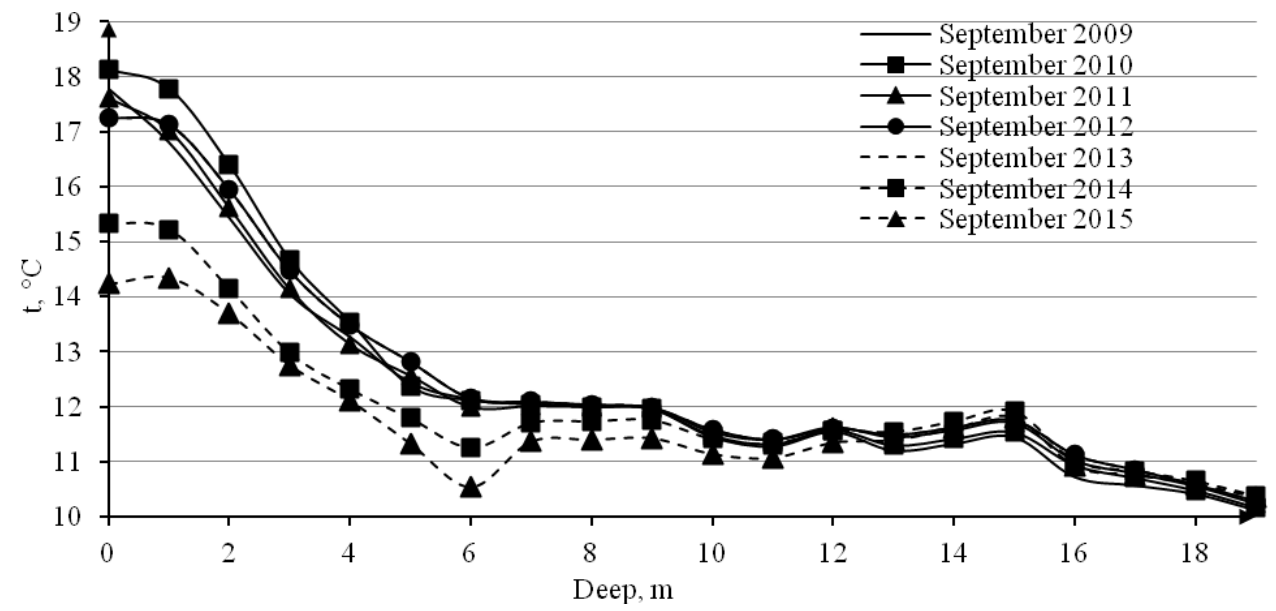

FiguRE 3. Site 1. Diagram of average monthly temperatures of soil mass in September for the 2009-2015

at intervals of $2 \mathrm{~m}$, to a depth of $3 \mathrm{~m}$ with intervals equal to $0.5 \mathrm{~m}$.

Monitoring of the temperature fields on site 2 has been carried out since August 2015. Currently monitoring data of temperature distribution in the soil mass has been obtained up to January 2016. Monitoring results (average monthly temperatures) are shown in Fig. 4 .

Analysis of monitoring results on site 2 displays the temperature of soil mass from a depth of $9 \mathrm{~m}$ as constant and equal to $6-7{ }^{\circ} \mathrm{C}$.

For further analysis the average monthly temperatures of soil mass for September 2015 are shown in Table 1 and Fig. 5 for both sites.

\section{Conclusions}

Based on the monitoring of the temperature regime of soils, conclusions are drawn:

(1.) The temperature of the ground for the second site is $+6-7^{\circ} \mathrm{C}$ and does not change over a depth of $9 \mathrm{~m}$.

(2.) The temperature of the ground of the first site is $+10-12{ }^{\circ} \mathrm{C}$ and does not change during the year from a depth of $9 \mathrm{~m}$. With the depth reading, the temperature decreases.

(3.) On the temperature regime of soils, the density of development of the territory under study has a significant influence. The higher temperatures of the ground massif of the first site are due to the proximity of the building of the Faculty of Civil Engineering with a heated basement. 


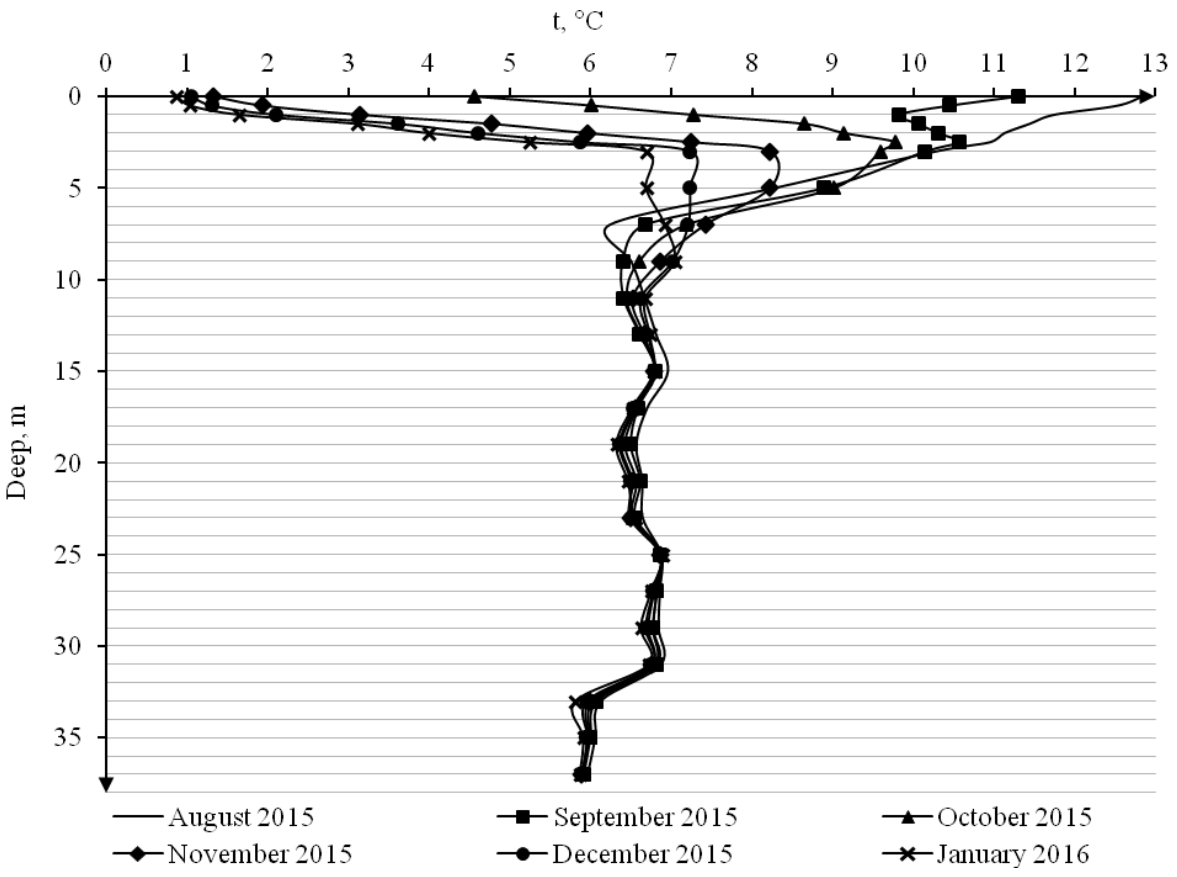

FIgURE 4. Site 2. Diagram of average monthly temperatures of soil mass according the monitoring results from August 2015 to January 2016

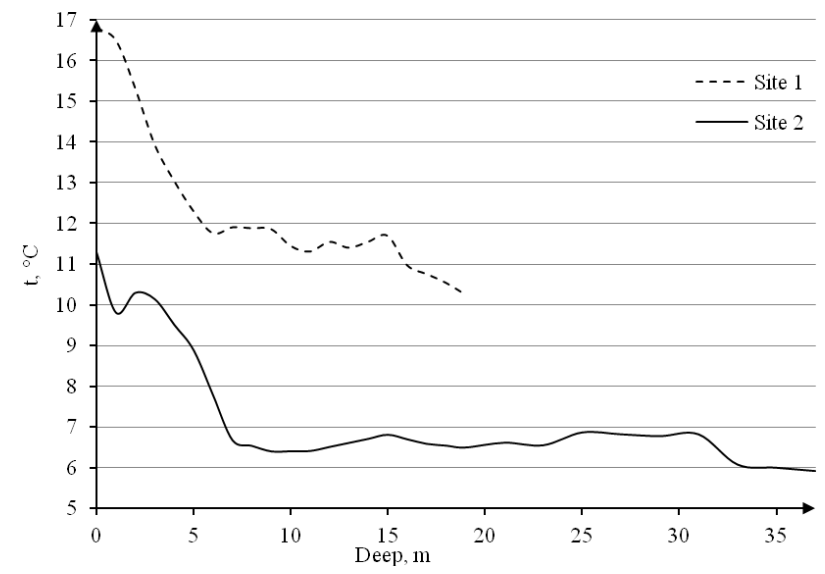

Figure 5. Diagram of average monthly temperatures in September for sites 1 and 2

\begin{tabular}{|c|c|c|}
\hline Depth & Site 1 & $\overline{\text { Site } 2}$ \\
\hline $\mathrm{m}$ & ${ }^{\circ} \mathrm{C}$ & ${ }^{\circ} \mathrm{C}$ \\
\hline$\overline{0}$ & 16.8 & 11.3 \\
\hline 1 & 16.5 & 9.8 \\
\hline 2 & 15.3 & 10.3 \\
\hline 3 & 13.9 & 10.1 \\
\hline 4 & 13.0 & - \\
\hline 5 & 12.3 & 8.9 \\
\hline 6 & 11.8 & - \\
\hline 7 & 11.9 & 6.7 \\
\hline 8 & 11.9 & - \\
\hline 9 & 11.9 & 6.4 \\
\hline 10 & 11.5 & - \\
\hline 11 & 11.3 & 6.4 \\
\hline 12 & 11.6 & - \\
\hline 13 & 11.4 & 6.6 \\
\hline 14 & 11.6 & - \\
\hline 15 & 11.7 & 6.8 \\
\hline 16 & 11.0 & - \\
\hline 17 & 10.8 & 6.6 \\
\hline 18 & 10.6 & - \\
\hline 19 & 10.3 & 6.5 \\
\hline 21 & - & 6.6 \\
\hline 23 & - & 6.5 \\
\hline 25 & - & 6.9 \\
\hline 27 & - & 6.8 \\
\hline 29 & - & 6.8 \\
\hline 31 & - & 6.8 \\
\hline 33 & - & 6.1 \\
\hline 35 & - & 6.0 \\
\hline 37 & - & 6.9 \\
\hline
\end{tabular}

TABLE 1. Average monthly temperatures of soil mass in September for sites 1 and 2 


\section{REFERENCES}

[1] H. Brandl, D. Adam, R. Markiewicz. Ground-sourced energy wells for heating and cooling of buildings. Acta Geotechnica Slovenica 3(1):5-27, 2006.

[2] R. Katzenbach, D. Adam, T. Waberseck. On the geotechnical conditions of construction in the city of perm. problems of soil mechanics and foundation engineering in difficult ground conditions. In Proc. of the International Scientific Conference dedicated to the 50th anniversary of BashNIIstroy 3-5 October. Ufa: BashNIIstroy, 2006.

[3] V. G. Shapoval, B. V. Morklyanyk. The temperature field in the soil base of heat pumps: monograph. Dnepropetrovsk: Porohy, 2011.

[4] A. B. Ponomaryov, A. V. Zakharov. Use of geothermal energy of soils for heating and air-conditioning of buildings. Bulletin of Volgograd State University of Architecture and Civil Engineering 17(36):119-122, 2010.
[5] A. Zakharov. Application of geothermal energy of the ground for heating of buildings in the climatic and engineering geological conditions of the perm region. Bulletin of Civil Engineers 2 (23) 2(23):85-89, 2010.

[6] R. Katzenbach, T. Waberseck, D. Adam, A. Ennigkeit. Innovationen bei der nutzung geothermischer energie durch erdberührte bauwerke, wie z.b. pfahlgründungen mittels energiepfählen. Geothermie-Symposium "Erdwärme - Energieträger der Zukunft", 25.11.2002 Bremerhaven / Bremerhavener Energiemanagement-Agentur. 2002.

[7] A. B. Ponomaryov, A. V. Zakharov. Analysis of the interaction of energy foundations in the geological and climatic conditions of the city of perm. PNRPU Bulletin 4:24-33, 2011. 